\title{
Impact of Urbanization and Industrialization on Agriculture
}

\author{
C. M. Jayadevan
}

\begin{abstract}
Industrialization and urbanization can influence the agricultural development. Industrialization and urbanization experienced in the last three decades really promoted the agricultural development. Using a sample of $\mathbf{1 1 5}$ countries over the period 1991-2018, this study verifies and finds the support for the hypothesis that industrialization and urbanization promotes agricultural development with the help of structural equation modeling.
\end{abstract}

Index Terms - Development, Industrialization, Urbanization, Structural, equation, modeling.

\section{INTRODUCTION}

Rapid industrialization and urbanization are important tools for achieving rapid pace of economic growth and development especially in a country where population is rapidly growing. Industrialization can transfer labour from the subsistence agricultural sector to the industrial sector [11]. Most countries have achieved high economic growth and development through urbanization and industrialization of economy. Throughout history, urbanization has been a key element in the process of development [2].

Urbanization is a complex socio-economic process that transforms the built environment, converting formerly rural into urban settlements, while also shifting the spatial distribution of a population from rural to urban areas. It includes changes in dominant occupations, lifestyle, culture, and behaviors, and thus alters the demographic and social structure of both urban and rural areas. A major consequence of urbanization is a rise in the number, land area and population size of urban settlements and in the number and share of urban residents compared to rural dwellers. The degree or level of urbanization is typically expressed as the percentage of population residing in urban areas [14]. Urbanization and development processes are inextricably linked- development does not occur without urbanization- although the casual link between these processes is not clear-cut [9]. Between 1950 and 2018 the world's population was urbanizing rapidly, with the proportion urban rising from 30 per cent in 1950 to 55 per cent in 2018 [14].

Does industrialization and concentration in space promote development? There are few econometric studies involving the impact of agglomeration on economic growth. Past studies show that spatial proximity is good for economic growth. There is a complementarity between economic

Published on July 30, 2020.

C. M. Jayadevan, Swinburne University, Australia.

(e-mail: devcmj@gmail.com) growth and urbanization. Martin and Ottaviano [12] show that growth and geographic agglomeration as "mutually selfreinforcing processes.". According to [7] "growth and agglomeration go hand-in-hand". In the review paper by [3] stresses that "spatial agglomeration is conducive to growth" given localized spillovers.

Bulhart and Federica [5]) explore the causal link running from agglomeration to growth, mediated by stage of development and openness using cross-section OLS and dynamic panel GMM estimation methods using dataset containing up to 105 countries over the period 1960-2000. The study finds evidence that supports the "Williamson hypothesis": agglomeration boosts GDP growth only up to a certain level of economic development. Another study by Crozet and Koenig [6] using the data for EU regions over the period 1980-2000 explore the effect of spatial concentration of economic activity within regions on the growth performance of these regions. The study shows that agglomeration is growth-promoting. Regions with a more uneven internal spatial distribution of production appear to grow faster.

Henderson's study[8] draws on panel data covering up to 70 countries over the period 1960-1990 using dynamic panel estimation methods finds that urbanization per se has no significant growth-promoting effect, but that urban primacy (the share of country's largest city) is advantageous to growth in low income countries. Their results support the Williamson's hypothesis-interaction terms with initial per capita income are negative for both urbanization and urban primacy. The study of [1] involving a cross-section of 85 countries indeed find a negative partial correlation between openness and urbanization.

According to [10] agglomeration matter more to closed economies than to open economies because domestic trading can be conducted cheaply over shorter distances than the international trade. The above studies show the role of urbanization in achieving development. Benefits of urbanization arise due to the presence of Marshallian externalities [8].

The primary aim of this research is to test a hypothesis that industrialization and urbanization promote agricultural development, though it reduces the share of agriculture in gross domestic product. This study provides new empirical evidence concerning the role of industrialization and urbanization in agricultural development for 115 countries over the period from 1991 to 2018 using structural equation modeling. This study will help to formulate policies to increase the industrialization and urbanization to achieve further agricultural development. Research on the role of industrialization and urbanization in the agricultural development is warranted for the following reason. There 
were no studies in the literature examining the role of industrialization and urbanization in the agricultural development using structural equation modeling. In this paper we address this limitation considering 115 countries for which comprehensive data are available. This study examines the role of industrialization and urbanization in the agricultural development using the structural equation modeling involving maximum likelihood methods for estimation instead of traditional econometric methods.

We develop the remaining discussions as follows: Section II describes the descriptive statistics. The basic model is summarized in section III. Section IV reports the results of the study. Section V summarizes the findings.

\section{DATA DESCRIPTION}

The data used in this study to measure industrialization and urbanization and agricultural development has been obtained from World Bank indicators statistics (2020). A brief description of variables are provided in Table 1.

TABLE 1: VARIABLES OF URBANIZATION, INDUSTRIALIZATION AND AGRICULTURAL DEVELOPMENT

\begin{tabular}{|l|l|}
\hline Variables & Description of Variables \\
\hline Urbanization (F_URBAN) \\
\hline UPP & Urban population (\% of total population) \\
\hline PUA & $\begin{array}{l}\text { Population in urban agglomerations of more than 1 million } \\
\text { (\% of total population) }\end{array}$ \\
\hline Industrialization (F_IND) \\
\hline GDPI & Industry (including construction), value added (\% of GDP) \\
\hline EMPI & Employment in industry (\% of total employment) \\
\hline Agricultural Employment and Output (F_EMP_OUT) \\
\hline V_EMPA & Employment in agriculture (\% of total employment) \\
\hline V_GDPA & Agriculture, forestry, and fishing, value added (\% of GDP) \\
\hline Agricultural and Forest Area (F_AREA) \\
\hline V_AGL & Agricultural land (\% of land area) \\
\hline V_FAL & Forest area (\% of land area) \\
\hline Agricultural Food and Livestock Production (F_FOOD_LIV) \\
\hline V_FPI & Food production index (2004-2006 = 100) \\
\hline V_LPI & Livestock production index (2004-2006 = 100) \\
\hline Source: Statistical Indicators Provided by World Bank. \\
\hline
\end{tabular}

The average urban population is $57.71 \%$. The lowest urban population is $5.49 \%$ which is almost eleven times lower than the average urban population. The range for urban population is between $5.49 \%$ and $100 \%$. There is a gap of $94.51 \%$ in urban population between minimum and maximum. The average urban agglomeration is $23.67 \%$. The lowest urban agglomeration is $2.17 \%$. The range for urban agglomeration is between $2.17 \%$ and $76.81 \%$. The gap between minimum and maximum urban agglomeration is $74.64 \%$. The coefficient of variation is highest for GDPA followed by EMPA and the lowest for FPI (Table 2).

TABLE 2: DESCRIPTIVE STATISTICS

\begin{tabular}{|c|c|c|c|c|c|c|}
\hline Variable & $\mathrm{N}$ & Mean & $\begin{array}{c}\text { Std } \\
\text { Dev }\end{array}$ & Minimum & Maximum & $\begin{array}{c}\text { Coeff } \\
\text { Variation }\end{array}$ \\
\hline UPP & 3220 & 57.71 & 22.61 & 5.49 & 100.00 & 39.179 \\
\hline PUA & 3220 & 23.22 & 14.44 & 2.17 & 76.81 & 62.188 \\
\hline EMPI & 3220 & 19.77 & 8.30 & 1.92 & 45.42 & 41.983 \\
\hline GDPI & 3220 & 29.43 & 12.38 & 3.24 & 87.80 & 42.066 \\
\hline EMPA & 3220 & 30.74 & 24.43 & 0.06 & 89.81 & 79.473 \\
\hline GDPA & 3220 & 14.04 & 13.47 & 0.16 & 79.04 & 95.940 \\
\hline AGL & 3220 & 43.51 & 20.48 & 2.66 & 85.49 & 47.070 \\
\hline FAL & 3220 & 28.39 & 20.95 & 0.01 & 73.69 & 73.794 \\
\hline FPI & 3220 & 101.27 & 25.59 & 7.05 & 206.96 & 25.269 \\
\hline LPI & 3220 & 101.50 & 26.19 & 4.48 & 245.50 & 25.803 \\
\hline
\end{tabular}

Source: Computed from Statistical Indicators Provided by World Bank.

\section{MODEL}

The Structural equation models include variables that are proportions, rates, and ratios. Modelling of such "compound" quantities is less straightforward than absolute quantities. So, all the variables are rescaled using the minmax normalization formula

$$
\mathrm{Yi}=(\mathrm{xi}-\operatorname{minimum}(\mathrm{xi}) / \operatorname{maximum}(\mathrm{xi})-\operatorname{minimum}(\mathrm{xi}) .
$$

This type of manipulation of data results in the interval $[0,1]$ for all the variables. Labels of rescaled variables are identified by adding a prefix "V_" to the original variables.

Does the industrialization and urbanization promote agricultural development research question is examined using structural equation modeling (SEM) during the period 1991-2018. The main reason for using the SEM method is necessitated by the use of latent variables in addition to manifest variables. A measurement model describes the nature of the relationship between a number of latent variables, or factors and the manifest indicator variables that measure those latent variables. The model investigated in this study consisted of five latent variables corresponding to the industrialization, urbanization, agricultural employment and output, agricultural cropped area and agricultural food production and livestock index. Following five latent factors are created using factor analysis.
F_IND
$=\left(V_{-}\right.$GDPI $+V_{-}$EMPI $)$
F_URBAN
$=\left(\mathrm{V} \_\right.$PUA + V_UPP $)$
F_EMP_OUT
F_AREA
$=\left(\mathrm{V} \_\right.$EMPA + V_GDPA $)$
F_FOOD_LIV
$=\left(\mathrm{V} \_\mathrm{AGL}+\mathrm{V} \_\mathrm{FAL}\right)$
$=\left(\mathrm{V} \_\right.$FPI + V_LPI $)$

Following set of structural equations were estimated and analysed.

$$
\begin{aligned}
& \text { F_EMP_OUT }=\text { b1 F_URBAN }+ \text { b2 F_IND + e1 } \\
& \text { F_AREA }=\text { b3 F_URBAN }+ \text { b4 F_IND }+ \text { e } 2 \\
& \text { F_FOOD_LIV }=\text { b5 F_URBAN + b6 F_IND + e3 } \\
& \text { F_EMP_OUT }=\text { b7 F_AREA + e4 } \\
& \text { F_FOOD_LIV }=\text { b8 F_AREA + e5 }
\end{aligned}
$$

Where F_IND is industrialization factor measured by two indicator variables-V_GDPI and V_EMPI; F_URBAN is urbanization factor measured by two indicator variablesV_PUA and V_UPP; V_EMP_OUT is agricultural employment and output measured by two indicator variables-V_EMPA and V_GDPA; F_AREA is agricultural cropped area measured by two indicator variables-V_AGL and V_FAL; V_FOOD_LIV is agricultural food and livestock production factor indicated by two indicator variables- V_FPI and V_LPI. All the manifest variables start with a prefix $\mathrm{V}_{-} *$. Details of these variables can be seen in Table 1. b1, b2, b3 ...b8 are parameters; and e1,e2,e3,e4 and e5 are the disturbance terms or residual path coefficients. Equations 1, 2 and 3 represent the initial measurement model testing the hypothesis that industrialization and urbanization promote agricultural development. Meaningful structural equations 2, 3, 4 and 5 are added to the initial measurement model to improve the model fit.

Data were analysed using the SAS 9.4 CALIS procedure, and the models tested were covariance structure models with 
multiple indicators for all latent constructs. Confirmatory factor analysis was used to develop a measurement model that demonstrated an acceptable fit to data [12]. The initial measurement model was modified to become a structural equation model representing the theoretical model of interest. This theoretical model was then tested and revised until a theoretically meaningful and statistically acceptable model was achieved. Parameters are estimated applying two-stage least squares.

\section{RESULTS}

Final structural equation model is identified or met the $\mathrm{t}$ rule criterion which states that sample moments or data points exceeds the number of free or distinct parameters. The number of data points is equal to the product of number of manifest variables and number of manifest variables plus one divided by two i.e., $((\mathrm{p}([\mathrm{p}+1]) / 2)$. The present analysis involves 10 manifest variables, 55 moments, 34 parameters and 3219 cases. The parameter to case ratio is 1:95. This means we have 1 parameter to 95 cases. Since this is getting over 10 we could argue that the sample size is acceptable, but this also depends on other assumptions being met such as multivariate normality. A plot of the Mahalanobis distances (Fig. 1) is given below. The distances are on the vertical and the chi-square quantiles are on the horizontal. This plot is approximately normal though there are few outliers at the right side of the plot and data satisfies the multivariate normality.

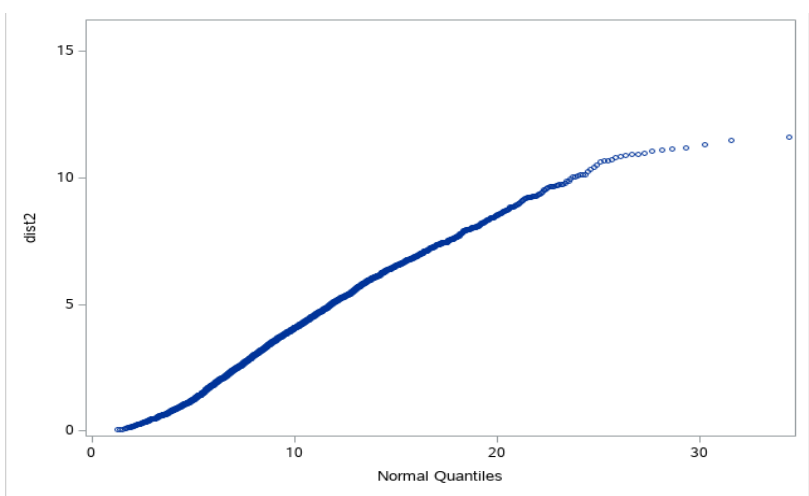

Fig. 1. Plot of the Mahalanobis Distance:1991-2018.

The standardized factor loadings for the indicator variables are also presented in Table.3. The standardized factor loadings range from -0.825 to 0.957 . None of these values are less than $|0.6|$. In fact, most of these values are above $|0.80|$. The variance extracted estimate for each latent variable is a measure of the amount of variance captured by a construct, relative to the variance due to random measurement error. All the constructs demonstrated variance extracted estimates in excess of 0.50 . These findings provide general support for the validity of constructs and their indicators. The variability in the endogenous variables is reported in the last column r-squared. The following table shows that $91.6 \%$ variance in agricultural employment and output is explained by the industrialization and urbanization. The industrialization and urbanization could explain $34.1 \%$ variance in agricultural cultivated area growth, $75.8 \%$ variance in agricultural food and livestock production (Table 3).

\begin{tabular}{|c|c|c|c|}
\hline $\begin{array}{c}\text { TABLE 3: FACTOR LOADING } \\
\text { Indicators }\end{array}$ & $\begin{array}{c}\text { Standardize } \\
\text { d Loading }\end{array}$ & $\begin{array}{c}\text { Variance } \\
\text { Extracted } \\
\text { estimate }\end{array}$ & R-Square \\
\hline F_URBAN & & 0.735 & \\
\hline V_UPP & 0.858 & & 0.704 \\
\hline V_PUA & 0.858 & & 0.295 \\
\hline F_IND & & 0.648 & \\
\hline V_EMPI & 0.805 & & 0.363 \\
\hline V_GDPI & 0.805 & & 0.234 \\
\hline F_EMP_OUT & & 0.786 & 0.916 \\
\hline V_EMPA & 0.886 & & 0.782 \\
\hline V_GDPA & 0.886 & & 0.418 \\
\hline F_AREA & & 0.681 & 0.341 \\
\hline V_AGL & 0.825 & & 0.493 \\
\hline V_FAL & -0.825 & & 0.270 \\
\hline F_FOOD_LIV & & 0.917 & 0.758 \\
\hline V_FPI & 0.957 & & 0.865 \\
\hline V_LPI & 0.957 & & 0.804 \\
\hline
\end{tabular}

In the present analysis, chi-square value of final model is 494.53 with 21 degrees of freedom, which is significant (i.e., p < 0.05). Because it is significant, technically we accept our null hypothesis of not good model fit. In other words, this test did not support our model on the basis of chi-square. The nomological validity of theoretical model is tested by performing a chi-square difference test in that baseline model is compared to an initial model and an initial model is compared to the final measurement model. A chisquare difference test comparing initial measurement model to baseline model reveals a significant difference value of 12118.476-796.658 $=11321.818(\Delta \mathrm{df}=45-23=22, \mathrm{p}<0.01)$. This finding shows that initial model provides a fit significantly better than the fit provided by baseline model. Similarly, a chi-square difference test comparing final measurement model to initial theoretical model revealed a significant difference value of 796.658$494.533=302.125(\Delta \mathrm{df}=23-21=2, \mathrm{p}<0.01)$. This finding shows that final structural equation model provides a fit to data that is significantly better than the fit provided by the initial model and baseline model (Table 4).

TABLE 4: GOODNESS OF FIT INDICES FOR VARIOUS MODELS

\begin{tabular}{|c|c|c|c|c|c|c|c|}
\hline Model & $\chi^{2}$ & df & $\Delta \chi^{2}$ & $\Delta$ df & CFI & SRMR & RMSEA(CL90) \\
\hline Baseline & 12118.476 & 45 & & & & & \\
\hline Initial Model & 796.658 & 23 & 11321.818 & 22 & 0.936 & 0.044 & $0.102(0.096-0.108)$ \\
\hline Final Model & 494.533 & 21 & 302.125 & 2 & 0.961 & 0.033 & $0.084(0.077-0.090)$ \\
\hline
\end{tabular}

Source:Computed from Statistical Indicators Provided by World Bank

Other goodness-of-fit indices for the structural equation models are also presented in Table 4. The CFI (Comparative fit index) is likely the most commonly reported incremental index. CFI values greater than 0.94 are suggestive of good fit between data and hypothesized models. The CFI value for the final model is ideal $(.96>.94)$. The SRMR (standardized Root Mean Square Residual) is an absolute index and is calculated as the standardized difference 
between observed and predicted correlation. The SRMR value for the final model 0.03 is ideal $(0.033<0.055)$. A commonly reported parsimony index is the RMSEA (Root Mean Square Error of Approximation). The RMSEA is one of the most informative goodness-of-fit indices because it considers overall error in the population. RMSEA values less than 0.09 are suggestive of fair or adequate error of approximation. Moreover, 90\% confidence limits (0.077 0.09 ) for the RMSEA are not within acceptable parameters range $(0.05-0.08)$. The RMSEA values are considered not acceptable.

It is still necessary to inspect specific features of the model results to see if any of the individual features fail to receive support even if most of the overall fit indices indicates good fit. Paths were deleted as per the results of Lagrange multiplier. In other words, this finding indicates that the relationships described in final model are successful in accounting for the observed relationships between the latent constructs.

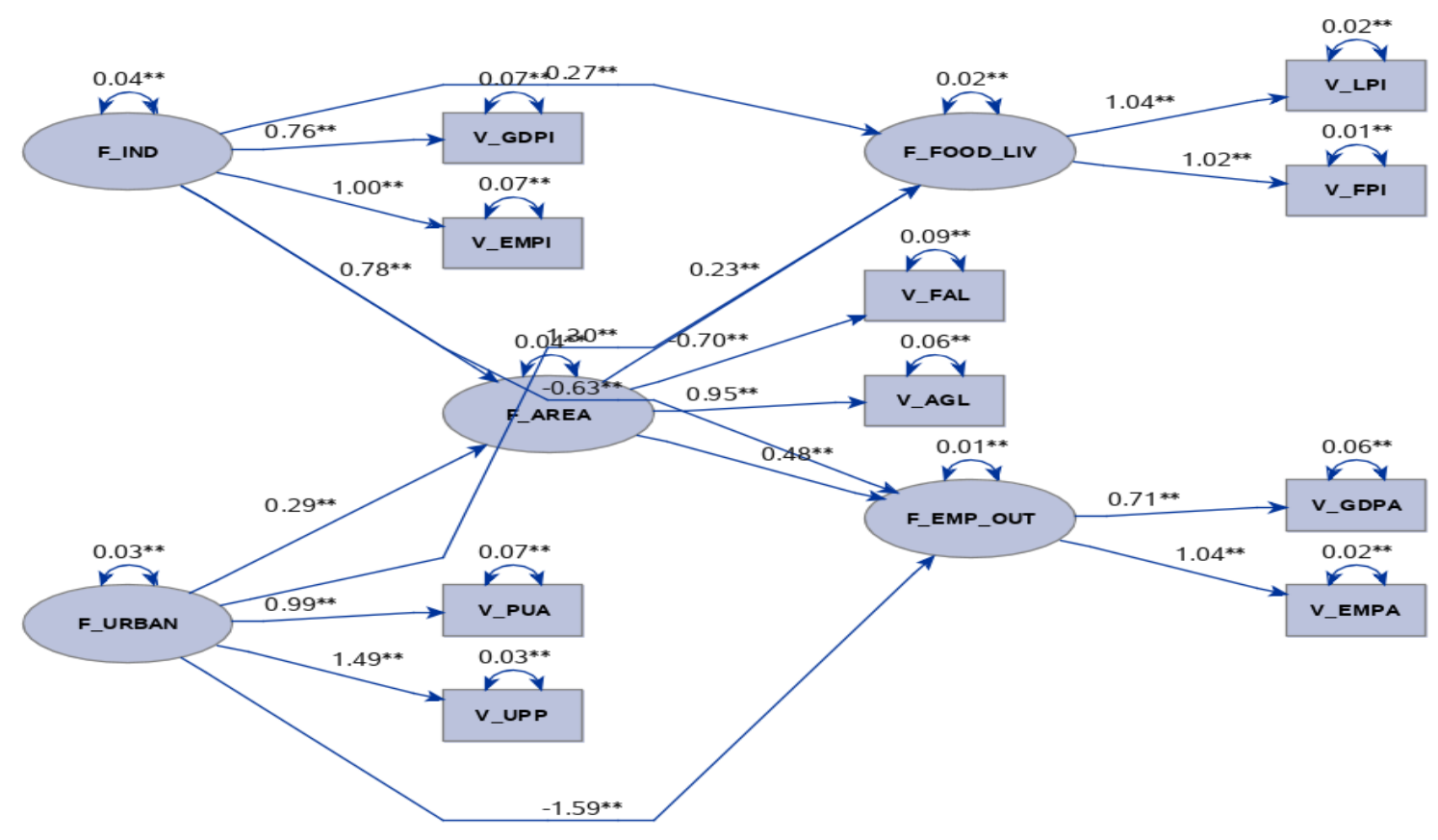

Fig. 2. Impact of Urbanization and Industrialization on Agriculture:1991-2018.

Figure 2 depicts non-standardized path coefficients of the final model. Path flow shows the coefficient of unstandardized coefficients reported in Table 5. A look at the Table 5 reveals that the contribution of factors to their respective indicators are positive except F_AREA. In case of F_AREA, its contribution to V_AGL is positive but negative in case of V_FAL. This is due to the rising deforestation caused by urbanization and industrialization.

The regression weight of urbanization on agricultural employment and output -1.59 in non-standardized model and -0.99 in standardized model. The regression coefficient of urbanization on agricultural employment and output is negative and significant. This indicates that for a one-unit increase in urbanization, there is a decrease of 1.59 units in agricultural employment and output in non-standardized model and there is a decrease of 0.99 units in standardized model which confirms the support for the hypothesis. The estimated structural equation model shows that urbanization reduces the share of agriculture in employment and output. Urbanization negatively and significantly contributes to reducing the share of agriculture in economic development. Similarly, the regression weight of industrialization on agricultural employment and output is -0.63 in nonstandardized model and -0.42 in standardized model. This also shows that industrialization also reduces the share of agricultural employment and output (Table 5).

The regression weight of urbanization on agricultural cultivated area is positive and significant. Similarly, the impact of industrialization on agricultural cultivated area is positive and significant. In fact, the impact of industrialization on agricultural cultivated area is stronger than that of urbanization. Urbanization reduced the size of forest area. Similarly, the impact of urbanization on agricultural food and livestock production is stronger than that of industrialization. Agricultural cropped area has a significant positive impact on agricultural employment and output. Agricultural cropped area also has a significant positive impact on agricultural food and livestock production. 
TABLE 5: RESULTS FOR PATH LIST

\begin{tabular}{|c|c|c|c|c|c|c|c|c|}
\hline \multirow{2}{*}{\multicolumn{3}{|c|}{ Path }} & \multicolumn{3}{|c|}{ Non-standardized Results } & \multicolumn{3}{|c|}{ Standardized Results } \\
\hline & & & Estimate & t Value & $\operatorname{Pr}>|t|$ & Estimate & $\mathrm{t}$ Value & $\operatorname{Pr}>|t|$ \\
\hline F_URBAN & $===>$ & V_PUA & 0.986 & 39.197 & $<.0001$ & 0.543 & 39.137 & $<.0001$ \\
\hline F_URBAN & $===>$ & V_UPP & 1.489 & 85.282 & $<.0001$ & 0.837 & 100.4 & $<.0001$ \\
\hline F_IND & $===>$ & V_EMPI & 1.005 & 22.510 & $<.0001$ & 0.602 & 23.382 & $<.0001$ \\
\hline F_IND & $===>$ & V_GDPI & 0.758 & 19.762 & $<.0001$ & 0.484 & 20.907 & $<.0001$ \\
\hline F_EMP_OUT & $===>$ & V_EMPA & 1.036 & 43.394 & $<.0001$ & 0.884 & 93.162 & $<.0001$ \\
\hline F_EMP_OUT & $===>$ & V_GDPA & 0.706 & 32.391 & $<.0001$ & 0.646 & 53.550 & $<.0001$ \\
\hline F_AREA & $===>$ & V_AGL & 0.949 & 39.565 & $<.0001$ & 0.702 & 34.917 & $<.0001$ \\
\hline F_AREA & $===>$ & V_FAL & -0.701 & -26.880 & $<.0001$ & -0.519 & -27.925 & $<.0001$ \\
\hline F_FOOD_LIV & $===>$ & V_FPI & 1.022 & 98.130 & $<.0001$ & 0.929 & 182.9 & $<.0001$ \\
\hline F_FOOD_LIV & $===>$ & V_LPI & 1.037 & 91.509 & $<.0001$ & 0.896 & 161.8 & $<.0001$ \\
\hline F_EMP_OUT & $<===$ & F_URBAN & -1.590 & -116.4 & $<.0001$ & -0.988 & -45.780 & $<.0001$ \\
\hline F_EMP_OUT & $<===$ & F_IND & -0.626 & -13.996 & $<.0001$ & -0.421 & -9.489 & $<.0001$ \\
\hline F_AREA & $<===$ & F_URBAN & 0.293 & 7.559 & $<.0001$ & 0.201 & 7.116 & $<.0001$ \\
\hline F_AREA & $<===$ & F_IND & 0.779 & 25.457 & $<.0001$ & 0.580 & 17.109 & $<.0001$ \\
\hline F_FOOD_LIV & $<===$ & F_URBAN & 1.305 & 106.9 & $<.0001$ & 0.806 & 68.592 & $<.0001$ \\
\hline F_FOOD_LIV & $<===$ & F_IND & 0.267 & 6.722 & $<.0001$ & 0.179 & 6.418 & $<.0001$ \\
\hline F_EMP_OUT & $<===$ & F_AREA & 0.478 & 11.601 & $<.0001$ & 0.432 & 10.044 & $<.0001$ \\
\hline F_FOOD_LIV & $<===$ & F_AREA & 0.231 & 7.717 & $<.0001$ & 0.207 & 7.858 & $<.0001$ \\
\hline
\end{tabular}

Source:Computed from Statistical Indicators Provided by World Bank

\section{CONCLUSION}

The estimated structural equation model shows that the transition of agricultural economy to modern economy depends industrialization and urbanization. All path coefficients between industrialization and urbanization on the one hand and agricultural development on the other are nontrivial and statistically significant. Overall goodness-offit indices like SRMR and CFI for the final model are ideal parameters. Moreover, the chi-square difference test shows that the final structural equation model provides a fit to data that is significantly better than the fit provided by the initial and baseline models. There is no serious collinearity issue in the regressions. Data also satisfies multivariate normality.

All the variables account for substantially high variance in agricultural development. Measures to increase industrialization and urbanization promote agricultural development. Industrialization produces various farm machinery and equipment required for agricultural mechanization and irrigation infrastructure. Industrialization also accelerates the production and consumption of chemical fertilizers which raise the productivity of farming. Urbanization induces the demand for agricultural products, raw or processed, either as raw material in factories or for direct consumption.

Industrialization and urbanization reduce the share of agricultural employment and output but increases the percentage of cultivated area and agricultural food and livestock production. It is notable that urbanization has a negative impact on the forest land. The urbanization programs in future must have adequate measures to ensure forest area is not destroyed. There were no past studies analyzing the relationship among industrialization, urbanization and agricultural development using the structural equation modeling, so this study provides new empirical evidence using a new methodology.
[3] Baldwin, Richard E., Martin,Philippe. (2004). Agglomeration and regional growth. In:Hendorson, Vernon J., Thissse, Jacques-Francois (Eds.). Handbook of Regional and Urban Economics, Vol.4:Cities and Geography. Elsevier, North-Holland.

[4] Bertinelli, L., Black, Duncan. (2004). Urbanization and growth. Journal of Urban Economics, 56(2004) 80-96.

[5] Brülharta, B Marius., Sbergami, Federica. (2009). Agglomeration and growth: Cross-country evidence. Journal of Urban Economics. $65,48-63$.

[6] Crozet, Matthieu, Koenig, Pamina.(2007). The cohesion VS growth trade off: Evidence from EU regions. Mimeo. University of Paris.

[7] Fujita, Masahisa, Thisse, Jacques-Francois. (2002). Economics of Agglomeration: Cities, Industrial Locations, and Regional Growth. Cambridge University Press.

[8] Henderson, J.Vernon. (2003). The Urbanization process and Economic Growth. The so-what question. The Journal of Economic Growth. 8(1), 47-71.

[9] Jacobs, J. (1969). The economy of cities. Random House. New York.

[10] Krugman, Paul,Elizondo, Raul Livas. (1996). Trade Policy and Third World Metropolis. Journal of Development Economics. 49(1), 137150.

[11] Lewis, W.A. (1954). Economic Development with Unlimited Supplies of Labour. The Manchestor Schools 22, 139-191.

[12] Martin, Philippe, Ottaviamo, Gianmarco, (1999). Growing Locations: Industry locations in a model of endogenous growth. European Economic Review. 43(2), 281-302.

[13] Rourke, Norm O'., Hatcher, Larry. (2013). A Step-by-Step Approach to Using SAS for Factor Analysis and Structural Equation Modeling. 2nd Edition. SAS.

[14] UN, World urbanization Prospects. (2018). The 2018 Revision, United Nations Publications. available from: https://population.un.org/wup/Publications/Files/WUP2018Report.pdf.

\section{REFERENCES}

[1] A. Ades, E. Glaeser.(1995). Trade and Circuses : explaining urban giants, Quarterly Journal of Economics 110 195-227.

[2] Bairoch, P. (1988). Cities and Economic Development: From Dawn of History to the present. Univ. of Chicago press. Chicago. 